\title{
HISTORIA DEL NO VIAJE: "DESDE LA PATRIA, AL CIELO" DE ANTONIO DE TRUEBA
}

\author{
Carmen Elisa Acosta P. \\ Departamento de Literatura \\ Universidad Nacional de Colombia
}

\begin{abstract}
"Cuán extraño debió resultar este Arte de la Escritura en su primera Invención lo podernos adivinar por los Americanos recién descubiertos, que se sorprendían al ver Hombres que conversaban con Libros, y a duras penas podían hacerse a la idea de que un papel pudiera hablar..."
\end{abstract}

Umberto Eco, Los límites de la Interpretación

\section{EL DIABLO MUDO}

Es una constante la manera como se puede asociar a través de la historia, la literatura con su peligro. También son innumerables los casos en los que grupos autoritarios han desplegado su poder en contra de la producción escrita y han señalado la división entre lo permitido y lo prohibido, entre lo bueno y lo malo, queriendo evitar así los riesgos sociales de la lectura. A su vez, hace parte de la tradición de las diversas sociedades y comunidades, a través de la 
historia, el adjudicar un lugar a la literatura y permitir su permanente revisión, construyendo desde las instituciones uno o varios cánones en los que se ubican las obras que bien por su carácter estético o bien por su carácter ético, son consideradas como las seleccionadas para permanecer en su función literaria ante el público lector. Nuevamente, de esta manera se señala lo que se debe y lo que no se debe leer.

La censura no siempre ha estado distante del canon. Son dos términos problemáticos, encargados de dar algún tipo de instrumentalización social a ese conjunto denominado lo literario. El canon probablemente esté cargado históricamente de una mayor movilidad cuando su preocupación está encaminada más al carácter estético que al ético de lo literario.

Uno de los ejemplos límite del efecto social de la pregunta por lo literario, sus peligros y efectos sociales, está dado en la elaboración, a través de los siglos, por parte de la iglesia católica de indices de libros prohibidos que fueron llevados a su uso extremo durante la Inquisición. Esta actitud, presente también en las diversas posiciones y confrontaciones de la institución en materia de lecturas, fundamentalmente en el campo de la educación, se ha encargado de señalar aquellas obras que no deben ser leídas para quien quiere pertenecer a la Iglesia y aspira al reino divino. Es interesante pensar en la defensa que realizaba ese 'diablo mudo' -como era denominado el escrito o a veces el libro en los procesos inquisitoriales-al que se le seguía un juicio análogo al de los escritores considerados herejes. ${ }^{1}$

Este peligro va unido al de la división entre alfabetas y analfabetas, entre aquellos 'virtuosos' que socialmente han tenido acceso al libro y que de alguna manera mediatizan su relación con el gran público ${ }^{2}$ lo cual ratifica sus privilegios.

\footnotetext{
${ }^{1}$ Concepto desarrollado por María Mercedes Rojas en su trabajo "Del escritor y otros demonios. Un estudio de la censura de escritos místicos en el siglo XVII y XVII". tesis de grado del deparlamento de literatura. Universidad Nacional de Colombia. 1998.

2 Roger Chartier, El mundo como representación, Barcelona, Gedisa, 1992.
} 
Es así como ha surgido la necesidad social de ejercer unos mecanismos de control a este objeto tan peligroso como es el libro, que puede constituirse en instrumento de manejo y de propaganda de ideas que atentan contra el orden establecido, tanto en el aspecto moral, ético y religioso como en el político. Este control hace parte de las diversas instituciones o agrupaciones sociales, pero también hacia el libro y los procesos lectores que proviene en muchos casos de la propia literatura.

Pero no se trata aquí de la extensa literatura que se ha ocupado del 'demonio de la lectura' que puede conducir a la locura, al desamor, al infierno y a la muerte. Cómo no tener presente el veneno con el que fueron elaboradas las palabras del Libro II de la Poética de Aristóteles refundido con celo en una Abadía medieval; el ama y la sobrina de don Quijote quemando una gran pila de libros luego de una purga de censura por parte del cura; como no tener en cuenta la tradición de la desafortunada Madame Bovary y sus anhelos de vida como personaje de novela. Así, la aproximación a la literatura propone un riesgo, más allá de una simple seducción, y la propia literatura se ha encargado de dar cuenta de él: el papel social de la literatura y del lector en su espejo frente al texto. Se trata de aquella literatura que propone una tesis sobre el papel del lector, su función y sus límites. Si bien la Inquisición durante mucho tiempo se encargó de delimitar dichos propósitos, fue también en el siglo XIX, y quizá como parte de una tradición, donde se formularon propuestas literarias que de manera unívoca señalaron los peligros de la lectura y se erigieron como ejemplos de lo permitido y lo prohibido, de lo bueno y lo malo, de lo que se debía y no se debía leer. Un ejemplo excepcional de dicha intención literaria es El cuento color de rosa. Desde la patria al cielo escrito por el "autor" español Antonio De Trueba, publicado en España en el año 1853, ${ }^{3}$ y editado nuevamente por entregas en el periódico neogranadino "El Mosaico", en el año 1858, versión a la cual me referiré a continuación.

\footnotetext{
Antonio De Trueba. (1813-1889). Nació en Montellano. Vizcaya, escribió además del libro de poemas El cantar de los cantares, novelas históricas entre las que se encuentran El Cid Campeador de 1851; Las fijas del Mio Campeador de 1854, La paloma y los Halcones de 1865. Juan Ignacio Ferreras, El triunfo del liberalismo y de la novela histórica (1830-1890). Madrid. Ed. Taurus, 1976, p. 97.
} 


\section{UN MOSAICO PARA LA NACIÓN}

El periódico literario "El Mosaico" fue fundado por José María Vergara y Vergara y Eugenio Díaz Castro el 24 de diciembre de 1858, con la colaboración de José Joaquín Borda y Ricardo Carrasquilla. Recibió este nombre por considerarse que en él se agruparían 'pequeños aciertos literarios'. La propuesta básica fue, entonces, la literatura y fue a partir de su concepción de donde surgieron las propuestas editoriales de la publicación.

Una de ellas, quizá la primera que se asumió, fue la de darle una amplia cobertura al periódico, y por eso sus fundadores decidieron realizar reuniones en las que participaba un amplio número de escritoras y de escritores. La primera reunión se realizó en casa de Rafael Elíseo Santander y posteriormente se establecieron de manera definitiva en la Imprenta de José Antonio Cualla. Dichas reuniones según Vergara se delimitaron por algunos principios que empezaron a señalar las características de los integrantes del grupo. En ellas se buscaba presentar y discutir diversas producciones literarias que serían preparadas para la posterior publicación. Se trataba de juegos literarios, variedades, anécdotas, cuadros de costumbres, poesías, biografías y novelas por entregas. Se elaboraron también textos no propiamente literarios como necrologías, bibliografías, traducciones, catálogos de novelas, comentarios culturales, publicidad a obras y chistes. Eran textos que de una u otra forma condicionaban la lectura de lo literario. Además de este objetivo se buscó "recuperar el honor perdido del chocolate", lo que de por si implicaba una relación afirmativa con el pasado español. Además y como norma inquebrantable se prohibió el consumo del licor y lo que era más importante, "hablar de política". Esto último, quizá lo más siginificativo para el papel social de la literatura, en un momento en el que se desarrollaban varios conflictos regionales: se establecía, en 1858, la Confederación Neogranadina, y las propuestas federales generarían tensiones que desencadenarían en la firma de la Constitución de Rionegro en 1863, en la que se creaban los Estados Unidos de Colombia. El período de publicación y lectura del periódico concuerda entonces, con el período que se ha denominado de "la revolución de medio siglo", en el que se confrontan, con la consolidación de los partidos políticos liberal y conservador, no sólo marcadas actitudes políticas como el federalismo y el centralismo; económicas como el librecambismo y el proteccionismo, sino religiosas y morales, en una permanente transformación de las ideas y de los valores. 
Desde entonces, de una comunidad de intereses, el programa editorial de "El Mosaico" tuvo tres puntos fundamentales: en primer lugar, la recuperación de la unidad nacional con base en la literatura. En segundo lugar, se buscó para el objetivo anterior, establecer una literatura nacional por medio de la recuperación de obras nacionales y la publicación del máximo de la producción contemporánea. En tercer lugar, se dio al periódico, y esto a partir de una proyección histórica hacia el futuro, un carácter de lectura no solo inmediata, sino que debía conservarse en un tomo para coleccionar y así lograr su permanencia en el tiempo.

Las personas que pertenecieron al grupo de los mosaicos no fueron siempre las mismas, ni todas escribieron de manera permanente y lo que es más importante pertenecieron a los dos partidos políticos. Se encontraron escritores que lo hicieron en contadas oportunidades como José Manuel Groot; hubo algunos más permanentes, que a veces se identificaron con su nombre propio o lo hicieron por medio del seudónimo. Son casos como los de José David Guarín (El Fisgón), Soledad Acosta de Samper (Andina), José Manuel Marroquín (Pero Pérez de Perales o P. P. de P), José Caicedo Rojas (Celta) o Ricardo Carrasquilla (Perico de los Palotes). Publicaron además, Januario Salgar, Manuel María Madiedo, Juan de Dios Restrepo, Juan Crisóstomo Osorio, Manuel Ancízar, Medardo Rivas, Salvador Camacho Roldan y Ezequiel Uricoechea.

La movilidad de los escritores tuvo que ver con las diversas épocas del periódico en las que se evidencia la necesaria combinación de la literatura con las artes y las ciencias. Es así como los intereses son expuestos en los cambios de título: El Mosaico. Miscelánea de literatura, ciencias y música (1858-1859); El Mosaico: al cual está unida la Biblioteca de Señoritas (1859-1860); El Mosaico: Album Neogranadino (1860); El Mosaico (1864-1865); El Mosaico. Periódico de industria, ciencias, artes, literatura e inventos (1865); y, por último, El Mosaico. Periódico de la juventud dedicado exclusivamente a la literatura (1871-1872).

Esta duración del periódico y la proliferación de escritos realizados por diversos autores, permite observar la importancia de la publicación periódica, y el desarrollo de una propuesta que el periódico utilizó sobre la literatura, su relación con los lectores y la manera como fue creando y transformando las expectativas lectoras. En periódicos como El Mosaico se construyeron a 
mediados del siglo XIX los lectores de literatura, donde la escribieron, leyeron y polemizaron jóvenes, maestros y estudiantes, escritoras, escritores y políticos. Allí socialmente se construyó el espacio de lo literario, donde se plantearon y cuestionaron las relaciones entre lo permitido y lo prohibido, entre lo público y lo privado. ${ }^{4}$

Antonio De Trueba ocupó un papel privilegiado dentro de la publicación que allí se realizó de autores extranjeros, puesto que uno de los propósitos fundamentales del periódico, en su primera época, fue impulsar a autores exclusivamente nacionales. Se divulgó también en El Mosaico la obra Nostalgia de De Trueba y se consideró al autor fundamental para la representación de problemas concernientes al costumbrismo como eran la relación del pasado con el presente, el campo y la ciudad, lo propio y lo extranjero y, lo más importante, la consolidación de la nacionalidad. La obra de De Trueba se adecuaba a los intereses lectores que intentaba consolidar socialmente "El Mosaico" y que en su intención de neutralizar los conflictos políticos, minimizaba también de alguna manera su relación con el pasado español.

\section{VIAJE DE REGRESO A LA INOCENCIA PERDIDA}

En la historia de la literatura han perdurado los personajes viajeros: viajó Ulises y retornó a su añorada Itaca, viajó Dante, viajó el picaro, viajó el caballero, viajó el Quijote. Tradicionalmente se puede restituir como característica fundamental de la novela esa relación del protagonista con el mundo y la manera como éste lo cuestiona. Tal intercambio, por demás conflictivo, lo problematiza interiormente. $^{5}$

"El viaje es, pues, un motivo y hasta un tema novelesco, pero también una estructura, por cuanto la elección de tal soporte argumental implica la organización del material narrativo en una textura fundamentalmente episódica: el viaje como resorte y eje estructurador de los extensos relatos." 6

\footnotetext{
${ }^{4}$ Para profundizar sobre el tema y la importancia del lector en "El Mosaico" sugiero remitirse a mi libro Lectores, lecturas y leídas: Historia de una seducción en el siglo XIX, Sanlafé de Bogotá, Icfes, 1999.

5 George Lukacs, Teoría de la novela. Barcelona, Ed. Grijalbo. 1970, p. 333.

6 Mariano Baquero Goyanes, Estructura de la novela actual. Barcelona, Planeta, 1970, p. 30.
} 
La reflexión sobre el papel social de la lectura y la relación con la constitución del espíritu nacional a partir de lo local fundamentado en los principios de la religión católica, fue el principio motor de la obra de Antonio De Trueba. Para este fin escogió, lo que fue útil dado el horizonte de expectativas y de lecturas del lector de cuya experiencia quería participar la estructura literaria del viaje.

En Desde la patria, al cielo, el joven Pedro abandonó todo: su provincia, su madre y su amada, para ir a buscar el mundo que en los libros creyó superior al propio. Las lecturas de Pedro provienen de un Indiano, viajero por excelencia, que a su vez encontrará la muerte en uno de sus viajes. "Por espacio de cuatro años había vivido casi constantemente encerrado en ella devorando millares de volúmenes entre los cuales los había de todos los géneros, útiles y nocivos, fruto de la ignorancia y de la sabiduría, de la imaginación extraviada y de la imaginación dirigida por buen camino". 7 La lectura, en la biblioteca del Indiano, había conducido al lector, propensa su imaginación a abultarlo todo, a que viajara por otros mundos rechazando su entorno nativo, minimizándolo. Estructura temática que permite establecer cierta relación con la tradición de El Quijote: Lector que inicia sus viajes forzado por la aventura que le han abierto los libros; y que desea transformar el mundo a partir de lo ya vivido en las lecturas: "...y asentose de tal modo en la imaginación que era verdad toda aquella máquina de aquellas soñadas invenciones que leía, que para el no había otra historia más cierta en el mundo...". ${ }^{8}$

Pero si bien Alonso Quijano emprende su viaje para desfacer entuertos y así llenar de gloria a su dama doña Dulcinea del Toboso, cuál es el motivo del viaje de Pedro? cuál es el de su búsqueda? Ratificar una ilusión, pero de ninguna manera transformar el mundo exterior. Se trata de la experiencia íntima de la religiosidad de Pedro durante el viaje. Este lo conducirá a conformarse con el trasegar de la vida, que al concluir debe conducirlo al reino divino, único viaje posible que señala el narrador para el lector: "Cuando terminado nuestro viaje, tornemos al cielo de Dios, las puertas del paraíso nos serán abiertas ...".9

\footnotetext{
7 Antonio De Trueba, "'Desde la Patria al Cielo". El Mosaico, Bogotá. 26 de marzo de 1859. No. 14, p. 120.

${ }^{8}$ Miguel de Cervantes Saavedra, El ingenioso hidalgo Don Quijote de la Mancha, Barcelona, Ed. Ramón Sopena. 1983, p. 46.

9 Antonio De Trueba, "Desde la Patria al Ciclo" El Mosaico, Bogotá, 26 de marzo de 1859, No. 14, p. 111.
} 
Fue así como se dio un efecto directo de la lectura en la mirada de Pedro, ${ }^{0}$ "sus ojos que desde lejos todo lo poetizan lo vulgarizan todo desde cerca". Decide salir de su terruño a reconocer en el mundo lo que le han mostrado los libros. El viaje del provinciano se convirtió en un proceso de desencanto, en el que se marcaron de manera radical las diferencias entre la literatura y la realidad. Fue desengaño el descubrir que el mundo presentado en las novelas no correspondía al mundo de la realidad, el cual estaba conformado por preocupaciones "prosaicas". En Francia inicia el desencanto ante las costumbres y el abandono de los ideales despertados por Nuestra Señora de París y El Judío Errante. No encontrará la fantasía de personajes como Guillermo Tell y los ventisqueros que tan bellos le habían parecido desde la biblioteca, le inspiraron horror en las montañas de Suiza. Ante el peligro de la realidad invoca la religión, a su madre y a Rosa, su amada. Igual desilusión sufrió en Grecia, donde "por la misma razón que había soñado más grande de lo que es en realidad, la encontró más pequeña de lo que en realidad es." En Inglaterra, el desencanto provino de la distancia con Walter Scott, de la diferencia de la religión católica con la protestante y las relaciones de trabajo que Pedro tuvo oportunidad de observar de explotación en las fábricas.

Como última esperanza viajó a América. El viaje de Pedro a Nueva York fue aprovechado por el narrador para hacer una burla a la libertad civil que permite la perversión moral que se hace pública por medio de la prensa que la acepta y la difunde.

Viajó a Suramérica en donde se encontró con la tradición española, primero en el reconocimiento de la lengua materna y luego en la religión. Se sintió identificado con los infortunios de América: "Como yo, abandonaste a tu noble y amorosa madre para ir a buscar el paraíso de tus sueños y el desengaño te va sumiendo, como a mí en honda melancolía. Ambos somos el hijo pródigo, que temblando de incertidumbre y remordimiento vuelve tímidamente los ojos al hogar de sus padres". ${ }^{11}$

\footnotetext{
${ }^{10}$ Una lástima no haber conseguido un ejemplar de la obra La desheredada (1881), la que según Iris Zabala. tiene como protagonista una mujer transmutada en Alonso Quijano femenino que devora novelas y folletines hasta el extremo de la identificación absoluta con los personajes que ha leído en las novelas (yo he leído mi propia historia tantas veces...) p. 387.

${ }^{11}$ Antonio De Trueba, "Desde la Patria al Cielo", El Mosaico, Bogotá, 28 de mayo de 1859, p. 188.
} 
Luego del desengaño debió volver a su hogar, su provincia y recuperar el amor de los suyos y la confianza en el trabajo humilde y las bondades que le ofrece la religión católica: "Malditos sean los libros y la sabiduría que no enseñan a amar y a consolar a los que nos aman y a bendecir la tierra en que nacimos". ${ }^{12}$

La estructura del texto de De Trueba está determinada por el carácter disquisitivo del narrador. La manera como éste va evidenciando los dispositivos que se proponen encerrar la interpretación del lector. La historia parte de un propósito en el que el narrador se sentirá elaborando una historia que busca demostrar algo, es una literatura que pretende un objetivo predeterminado y que por consiguiente se plantea como unívoca.

Los espacios vacíos del texto deben ser llenados por el lector en tres niveles: por una parte, lo que corresponde a la experiencia de los personajes de la provincia, en particular las del viajero Pedro; en segundo lugar, la estructura que enmarca el texto, a manera de simulación epistolar en la que el narrador se dirige a la 'rosa de sus sueños ${ }^{13}$ y que remite al tercer nivel que es el marco de la construcción de un lector explícito, a partir de señalamientos directos por parte del narrador, en los que ataca de manera directa su concepción de la provincia, de la lectura y del papel de los libros para su concepción de la vida y de la realidad. Es entonces aquí, más importante el marco narrativo de la obra que el personaje y su experiencia, más importante que el lector, es el narrador que interviene ideológicamente en la construcción del relato contribuyendo a la interpretación y al análisis de la experiencia vivida por Pedro.

No es gratuito, entonces, que el narrador se dirija desde el inicio del texto al "lector despreocupado", al que adjudicó ciertas previsiones que sólo eran posibles en un lector que podía eventual mente juzgar como negativos los valores de las

\footnotetext{
12 Ibid. p. 189.

13 Una vez anunciado este hecho, llamarse Cuentos color de rosa, aparece en la publicación de El Mosaico la siguiente cita a pie de página, elaborada por los editores del periódico: "'Llama de esta manera el autor a una Colección inédita de cuentos morales que. por estar escritos para alivio y consuelo de las almas sensibles, e ir dirigidos a una rosa de sus pensamientos en quien es ingénita la ternura, presentan al mundo su aspecto rosado, sirviendo como de antítesis a tantos otros que sólo revelan lo repugnante y deforme de la sociedad." El Mosaico, Bogotá, 26 de marzo de 1859. No. 14, p. 110.
} 
pequeñas provincias españolas: "No es verdad lector despreocupado, que tienen razón los franceses cuando dicen que el Africa comienza en los Pirineos?". ${ }^{14}$ A continuación, señaló de manera directa el tipo de lector ideal al que se dirigía su obra: "Lector despreocupado! No quiero dirigirme a ti porque tu no me comprendes. No quiero escribir para ti porque soy pobre de espíritu y rico de corazón, y sólo para los pobres de espíritu y ricos de corazón escribo". ${ }^{15}$ Quizá el lector despreocupado es aquel que no ve con preocupación las transformaciones que se están dando en su propia época.

Los libros que lee Pedro provienen de un espacio diferente e independiente, que rompe con la regularidad del pueblo: la casa del Indiano sobresale de las otras, el Indiano, viajero que ha obtenido sus riquezas fuera de la provincia es un hombre solitario, sin familia: "Ves estos libros Teresa?... cuidádmelos con esmero, que ellos han sido siempre y son y serán mis mejores amigos: a ellos debo la tranquilidad de mi alma. Lo que vosotros, pobres aldeanos, que nunca habéis visto sabios llamáis mi sabiduría y hasta las riquezas que aquí y en América poseo". ${ }^{16}$ Por qué los mismos libros surten un efecto opuesto en Pedro que en el Indiano?

Es fundamental señalai* la experiencia de la no lectura. La madre de Pedro, imagen central de religiosidad y centro del mundo natural de la provincia no lee, es analfabeta. ${ }^{17}$ El cura en su descripción se hace importante por las lecturas que no ha realizado, la aproximación al mundo de lo que no ha leído. Así se contribuye al ataque del imaginario de lo contemporáneo:

"El cura de la aldea es un viejecito que no lee periódicos políticos, ni conoce a Prudhon, ni a Fourier, ni ha saludado a los filósofos alemanes; que no comprende la filantropía inglesa; que se ríe de los Catones americanos y de los rejeneradores europeos; que se sabe de memoria todas las vejeces de la Biblia...". ${ }^{18}$

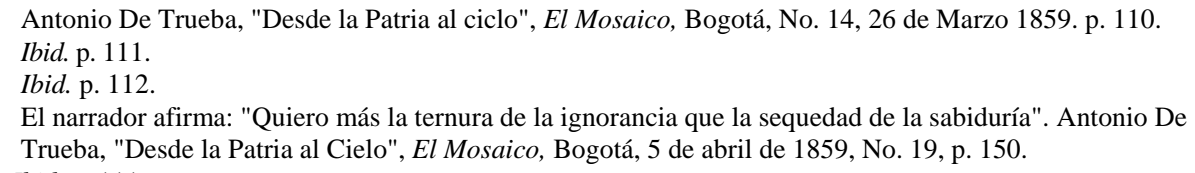


En casa de los aldeanos se encuentran los siguientes libros: el catecismo Astete, los Gritos del Purgatorio, el Año Cristiano, Don Quijote y los Fueros de Vizcaya. Los libros que lee Pedro le construyen una realidad poblada de fantasmas:

"Nosotros habitamos las montañas de Suiza, donde vaga la sombra de Guillermo Tell; las márgenes de Rin pobladas de sílfides y de wilis; los canales de Venecia donde aún resuena el canto de los gondoleros; las ruinas del circo romano teñidas con la sangre de los mártires; el golfo de Perténope sombreado por el laurel de Virgilio; los harenes y jardines de Bizancio; la santa Palestina donde viven aún Jesús y Godofredo y Pedro el Ermitaño: la Grecia, patria de los dioses y los semidioses, la India, tierra de los ríos sagrados y las piedras preciosas, y la América último refugio de los gobiernos patriarcales y único teatro de las escenas de la naturaleza...". ${ }^{19}$

\section{EL NO - VIAJERO, SE CANCELA LA BÚSQUEDA}

La tradición de los viajeros españoles que quizá se solidificó con las campañas de descubrimiento y conquista a partir del siglo XV, adquirió nuevos propósitos con el ingreso al XIX. El viajero buscaba el escapismo de la sociedad actual, un cambio de los valores europeos en todos los órdenes religiosos, literarios, éticos, sexuales y sociales. Se buscaba en el tiempo y en el espacio lo que no se encontraba en la sociedad contemporánea. ${ }^{20}$ El viaje implicaba movimiento, aventura y quizá lo que era más apetecido pero también más peligroso, imaginación. De Trueba propuso esta búsqueda no huyendo, ni saliendo de la tradición sino por el contrario permaneciendo y adentrándose en ella. En su oposición planteó al no-viajero, al personaje que debía cancelar la búsqueda, al antihéroe épico por excelencia.

Se trató de un cuestionamiento del mundo europeo, se buscaba la permanencia de unos puntos de referencia más universales como por ejemplo la religión y la lengua, que con la diversidad de perspectivas y comparaciones que se daban

\footnotetext{
${ }^{19}$ Ibid, p. 120.

20 Lily Litvak, Geografías mágicas. Viajes españoles del siglo XIX por países exóticos (1800 - 1 1913).Barcelona, Ed. Laertcs. 1984, p. 15.
} 
para un viajero podían hacerse cada vez más relativas. Fue así fundamental determinar los niveles de comparación entre un mundo real y uno idealizado.

Pero a la vez para un lector interesado y habituado a los libros y a la literatura de viajes, que quizá vivía en ellos sus experiencias y emociones, De Trueba propuso el no viaje de la no lectura. A partir de la estructura de viajes consolidó un texto que era aporía del proceso de lectura: un lector ante un texto que lo previene de los riesgos y las falsedades de la lectura, y a la vez el señalamiento de los peligros y riesgos de otro viajero, quizá más importante, el lector-viajero. No por otra razón De Trueba se cuidó de que en su texto aparecieran los motivos indispensables del viaje: el itinerario, el equipaje, las despedidas, la relación con el paisaje, el sentimiento del forastero, el problema de la hospitalidad, el intercambio de ideas, la relación con otras lenguas y creencias. la patria lejana, la soledad, la añoranza y el retorno. ${ }^{21}$

El itinerario del viaje de Pedro se realizó con poco equipaje, unas novelas a las que recurre cuando duda que la realidad que encuentra sea tan distinta a la leída. La actitud del personaje no estará en discordancia con la de los viajeros de la vida real. El viajero literario y el de los libros de viaje relataba también lo que era muy usual, el hecho de ir acompañado de sus libros preferidos y no en pocas ocasiones le servían como mediación a sus propias experiencias frente a la realidad. Se puede poner como ejemplo, el viaje del francés Pierre D'Espagnat a la Nueva Granada, que viaja leyendo a María. novela del escritor Jorge Isaacs, y así observa el mundo desde la literatura.

El lector fue señalado desde el inicio del texto como aquel que se dejó absorber por la construcción de un espacio a partir de la palabra. No podrá tener otro referente de la provincia de Pedro que la información de un libro, el diccionario geográfico, una visión parcial de la realidad, para ese lector, viajero en potencia:

"Aquí tienes todas las noticias geográficas, históricas, estadísticas. etc. que dan los libros acerca del rinconcito del mundo de que vamos a hablar.

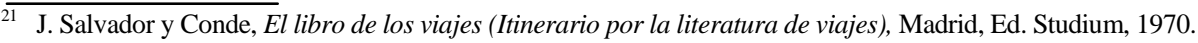


Pero como del consejo de S... me interesa algo más que a los autores de Diccionarios geográficos, voy a suplir el desdeñoso laconismo de esos señores.

Verdaderamente el consejo de S... no tiene grandes títulos a la atención del viajero y sobretodo si el viajero es despreocupado como tu". 22

Se manejan entonces dos niveles de lo verosímil. ${ }^{23}$ El construido por las palabras en el relato del viaje de Pedro, donde se expone una realidad 'aparentemente real' pero no menos literaria, que el segundo nivel de lo verosímil, anulado por el propio texto, que es el construido por las lecturas que Pedro realiza en la biblioteca del Indiano. El viaje de la lectura se constituye en un viaje del alma, la imaginación y la emoción: "Plutarco y Homero habían arrastrado su alma Grecia; el ignorado autor de las Mil y una noches la había llevado por las regiones asiáticas de delirio en delirio y de asombro en asombro; Chateaubriand la había paseado por las vírgenes soledades de América; Cook la había hecho dar la vuelta al mundo, sumergida en el sublime horror de las tinieblas y los hielos polares, y Schiller, Goethe, Hoffman y Shakespeare habían hecho comparecer ante ella todos los fantasmas, ora risueños, ora terribles, de los países teutónicos y británicos". ${ }^{24}$

El conflicto de estos dos niveles se resuelve en la temporalidad, el proceso de lectura y el posterior viaje, pero más aún en la espacialidad, la toma de distancia que permite la comparación espiritual de los dos mundos, a la vez que la distancia espiritual de los verdaderos valores. El camino que ha recorrido Pedro parte del aparente crecimiento espiritual que le aportan las lecturas, desciende a la experiencia material propiciada por el viaje y nuevamente retorna a la reconstrucción espiritual determinada por el reconocimiento y la aceptación de los valores promovidos por el catolicismo. A diferencia de don Quijote, Pedro se va desencantando simultáneamente en el viaje...

La descripción de la provincia está marcada como el espacio autónomo, ideal, que permite estar detenido en el tiempo. Se inicia por la iglesia, luego el río, donde no hay nada de extraordinario ni de exótico, "pues aunque parezca increíble

\footnotetext{
${ }^{22}$ Antonio De Trueba, "Desde la Patria al Cielo", El Mosaico, Bogotá, 9 de abril de 1859, No. 16, p. 110. 23 Gerard Genelte, "La estructura liberadora: lo verosímil en la Jerusalén Liberada de Tasso", Lo verosímil, Buenos Aires, Ed. Tiempo Contemporáneo, 1970 "Desde la Patria al Cielo", El Mosaico, Bogotá, 5 de abril de 1859, No. 16, p. 127.
} 
en un siglo tan civilizado como el nuestro, también enamora semejante río a los habitantes de S...!". ${ }^{25}$ Para concluir, se adelanta a las expectativas e intereses del lector contemporáneo: en cuanto a preciosidades históricas y monumentales están conformadas por un castaño que plantó el padre el día que nació Pedro, un rosal que plantó su madre un día que Pedro estaba enfermo, un rótulo en el puente recordando el día que un Fulano salvó a un Sutano al arrojarse al río, y la ermita de San Roque. En oposición al imán que podía cautivar al viajero de la época consolidado por lo exótico y diferente, aquí se señala lo elemental como lo fundamental, lo reconocido por todos, la tradición. Por último, se describen las gentes que habitan en la provincia, sin ninguna carga heroica, ni de especial interés que los haga estar en armonía con el espíritu del siglo.

La construcción del lector como personaje y las lecturas que realizó como parte de su acontecer en el texto, fueron resultado de la conciencia que socialmente se tuvo sobre la influencia del acto de leer. Este se estimuló como el medio por el cual el individuo podía acceder a determinadas conductas necesarias en la construcción de la nacionalidad.

Escritores contemporáneos de De Trueba como Gil y Carrasco, con sus personajes en permanente añoranza de la tierra natal y viajeros como Pedro de Alarcón, comparten ese espíritu nacional construido por la presencia social del viajero: "...los que así pensáis todavía, salid de vuestra patria; recorred ajenas ciudades; estudiad extrañas costumbres y veréis y sentiréis que la patria existe, que cada hombre tiene una patria como tiene una madre y que esa patria y esa madre no se pueden reemplazar por otra". ${ }^{26}$

Pero por otra parte, fue una escritura que buscó expresarse en oposición a la sociedad actual, y que con base en ella propuso la civilización como bandera y se apoyó en la literatura para exponer sus propósitos políticos. En una vana intención de ironía, el narrador, homologable quizá al autor, se preocupa por el 'espíritu del siglo.'

25 Ibid, p. 110.

${ }^{26}$ Pedro de Alarcón, Antología, Selección y prólogo de Juan del Corral, Madrid. Ediciones Fe, MCMXLV, p.47. 
Fue José de Castro y Serrano quien en un artículo reseñando la publicación de los Cuentos Color de Rosa se refirió a De Trueba como el Hernán Cortés de la literatura y como aquel que permitió que ésta volviera a ser honrada. En su interpretación señala el defecto de la obra de De Trueba: "Pedro leyó, y leyó mal; Pedro deseó salir al mundo y deseo bien: Pedro viajó, y viajo mal; Pedro deseó volver a su patria y deseó bien". El problema está señalado en el lector, no en el mundo, en la educación que ha recibido. Aún más, enfático afirma el reseñista: "Esto Antonio es negar el progreso y las ciencias y las artes, y la industria y la civilización que, en último término es la moral humana". ${ }^{27}$

Se opusieron entonces dos tipos de lectores: por un lado, los que se produjeron ante los textos que hacía parte de la tradición y que tenían como fundamento la tradición católica y que contrarrestaban al otro tipo de lector, el contemporáneo, a partir de más lecturas.

Se hizo explícita entonces en la obra de De Trueba la preocupación constante del costumbrismo en la construcción de un espacio narrativo de desplazamiento. Es una constante el rechazo de los costumbristas a Madrid, ya que consideran que se parece mucho al resto de Europa. El ambiente de la capital no es propicio al ejemplo virtuoso. ${ }^{28}$ Se puede recordar al respecto el cuento de De Trueba "Nostalgia", ${ }^{29}$ en el que el niño de provincia es llevado a la ciudad donde muere recordando su tierra natal, de nostalgia, de soledad y por el mal trato que recibe.

El narrador en los textos costumbristas por lo regular es un viajero, algunas veces del campo, que por su condición se somete a los sufrimientos inevitables de la ciudad y que debe retornar a su lugar de origen apreciando lo que por su abandono no había valorado, o que fatalmente muere por los rigores de la ciudad. Pero más usual es que éste sea un ciudadano nacional o extranjero, portador por demás de la habilidad del escritor para elaborar cuadros, que se desplaza con las mejores

\footnotetext{
${ }^{27}$ José de Castro y Serrano, "'Cuentos de Color de Rosa, por Don Antonio De Trueba; y final de la otra vida, cuento de viejos". El Mosaico. No. 47. 27 de noviembre de 1859, p. 376.

${ }^{28}$ Iris Zavala, Romanticismo y realismo. Barcelona, Ed. Crítica, 1982, p. 367. Juan Ignacio Ferreras, El triunfo del liberalismo y de la novela histórica (1830 -1870). Madrid, Taurus, 1976, p. 177. Quizá en contra del centralismo castellano se propone una interpretación un tanto patriarcal y tranquila del pueblo vasco. 29 Antonio De Trueba, "'Nostalgia", El Mosaico. Bogotá, No. 1, Enero 7 de 1860, p. 2-5.
} 
comodidades, nunca a quedarse y siempre a retomar, con un ideal o con el material para escribir un nuevo cuadro. El costumbrismo se basó en el conocimiento o reconocimiento de espacios por medio de la comparación con el otro, así no entrara en contacto con él.

Se han señalado varias estrategias narrativas, convenciones y constantes con las que se construyeron los escritos denominados costumbristas: la exactitud espacio-temporal, la linealidad cronológica, las generalizaciones en las que un hecho vale por todos, resaltar con la mirada acontecimientos que en apariencia pueden pasar desapercibidos, señalamientos morales y didácticos, búsqueda del humor, detallismo en el que prima la descripción sobre la acción, uso de señales tipográficas para los términos regionales y la construcción de diálogos tipos que se reiteran sin necesidad de crear espacios particulares. Los textos eran creados bajo el propósito fundamental de convencer, y solo a partir de él, se lograba la conformación de una realidad literaria, la "copia de la realidad". Copia en la que un sentimiento particular se hace colectivo, al igual que la afirmación de Fernán Caballero, que fue tan difundida en América "Los cuadros de costumbres no se inventan, se copian."

Pero lo fundamental aquí, en la construcción de la espacialidad está la manera como se establece la relación entre el mundo de la naturaleza y el mundo divino, opuesto este último al de la cultura representado por las novelas.

Esta concepción de la falsedad desde la literatura está determinada por la oposición a un intento por parte del realismo, de correlacionar de manera directa el mundo novelesco y la realidad, imprimiéndole a la literatura una funcionalidad más política. De Trueba hacía parte de la tensión propiciada por el romanticismo entre civilización y barbarie, que en su obra se propuso como la necesidad de optar por lo primitivo, no en un mundo exótico, exterior, sino en el de la provincia natal. Esta oposición se agudizó en la diferencia entre lo culto, que de todas maneras se hacía innecesario y lo popular, que sin mayor realce permitía el acceso a la felicidad de lo sencillo y carente de conflicto. 
Pero también quizá se oponía a ese sentimiento romántico de la vida concebida como destien-o, como tragedia y agonía; ese sentido de quebrantar la rutina, aceptar ciegamente lo novedoso, ambicionar constantemente una nueva vida.

Podría concluirse que lo que pretendió el texto de De Trueba fue conducir el proceso de interpretación del lector. Ponerle límites a sus conjeturas en la importancia que se le daba en la conformación del texto a la representación de la lectura. La literatura buscó entonces, cumplir una función social explícita: poner atención y control a los discursos que circulaban a través de los libros. Se trataba de combatir la novela con más novela. De Trueba fue el escritor que eligieron los neogranadinos de "El Mosaico " para consolidar dicho propósito. 


\section{BIBLIOGRAFIA}

Acosta, Carmen Elisa, Lectores, lecturas y leídas: Historia de una seducción en el siglo XIX, Santa Fe de Bogotá, Icfes, 1999.

Alarcón, Pedro de, Antología, Selección y prólogo de Juan del Corral, Madrid, Ediciones Fe, MCMXLV.

Baquero Goyanes, Mariano, Estructura de la novela actual, Barcelona, Planeta, 1970.

Chartier, Roger, El mundo como representación, Barcelona, Gedisa, 1992.

Cervantes Saavedra, Miguel de, El ingenioso hidalgo don Quijote de la Mancha, Barcelona. Ed. Ramón Sopena, 1983.

De Trueba, Antonio, "Desde la Patria, al Cielo", El Mosaico, Bogotá, No. 14, Mayo 28 de 1858, y "Nostalgia", El Mosaico, Bogotá, No. 1, Enero 7 de 1860.

Ferreras, Juan I., El triunfo del liberalismo y de la novela histórica (1830-1870), Madrid. Taurus, 1976.

Genette, Gerard, "La estructura liberadora: lo verosímil en la Jerusalén Liberada de Tasso". Lo Verosímil, Buenos Aires, Ed. Tiempo Contemporáneo, 1970.

Litvak, Lily, Geografías mágicas. Viajes españoles del siglo XIX por países exóticos (1800-1900), Barcelona, Ed. Laertes, 1984.

Lukacs, George, Teoría de la novela, Barcelona, Ed. Grijalbo, 1970.

Rojas, María Mercedes, "Del escritor y otros demonios. Un estudio de la censura de escritos místicos en el siglo XVII y XVIII", Santafe de Bogotá, tesis de grado, departamento de literatura, Universidad Nacional de Colombia, 1998.

Salvador y Conde, J., El libro de los viajes (Itinerario por la literatura de viajes), Madrid. Ed. Studium, 1970.

Zavala, Iris, Romanticismo y realismo, Barcelona, Ed. Crítica, 1982. 